\title{
Ao terror do outro respondemos com pedradas cegas: notas sobre o desconforto na poesia portuguesa contemporânea
}

Joana Matos Frias

Universidade do Porto

tout en étant liée substantiellement au monde, la littérature est ailleurs; sa fonction, du moins au sens de cette modernité qui commence avec La Bruyère, n'est pas de répondre directement aux questions que le monde pose, mais, à la fois plus modestement et plus mystérieusement, d'amener la question au bord de sa réponse, de construire techniquement la signification sans cependant la remplir. [...] la lumière qui est jetée par l'écriture sur le malheur humain reste indirecte, issue la plupart du temps d'une conscience aveuglée, impuissante à saisir les causes, à prévoir les corrections; mais cet indirect même a une valeur cathartique, car il préserve l'écrivain de la mauvaise foi: dans la littérature, à travers elle, l'écrivain ne dispose d'aucun droit, la solution des malheurs humains n'est pas pour lui un Avoir triomphant: sa parole est seulement là pour désigner un trouble. C'est ce qu'a fait La Bruyère: parce qu'il s'est voulu écrivain, sa description de l'homme atteint les vraies questions.

Roland Barthes, "La Bruyère". 


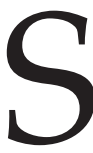
e existe evidência que a história da arte e da literatura nos tenha ensinado a enfrentar, ela estará certamente no facto de essa história nos exigir uma visão dialéctica que não procure branquear o estado antitético essencial que compõe a criação e a meditação estéticas e poéticas ao longo dos tempos. Significa isto que, desde as coisas primeiras que Aristóteles tanto apreciava, é possível isolarmos um conjunto de "bivalências moventes", usando o conceito de B. Munteano ${ }^{1}$, que accionam as correlações históricas e artísticas de variabilidade e permanência e que explicam a ambivalência e a ambiguidade estruturantes dos períodos. Assim, a obra na sua relação com o tempo e com a História não é dissociável da dualidade heterogénea que vincula os pólos aparentemente antagónicos de dicotomias tão ancestrais como natureza-arte, invenção-imitação, inspiração-trabalho, razão-emoção, indivíduo-sociedade, individual-universal ou utilidade-prazer.

Sabemos como Horácio quase conseguiu congelar algumas destas dicotomias, iniciando um processo de constituição da poética clássica normativa que teria o seu clímax, mas também o seu canto do cisne, no pensamento e na doutrina neoclassicistas do século XVIII. Não por acaso, foi justamentena sequência desse canto do cisne que a Modernidade pôde emergir em todo o seu esplendor, num século XIX que a partir do Romantismo se viu obrigado a reequacionar e a repensar criticamente o valor estético das categorias e dos sistemas estilísticos. Enão foi certamente por acaso também, que, no âmbito desse debate em que o problema da imaginação tomou conta da reflexão sobre os processos de criação artística, houve dois pares de conceitos cuja contraposição se agudizou, gerando fileiras de um lado e de outro, e abrindo uma discussão que se prolongaria pelos momentos mais importantes da literatura do século XX, e que, nos nossos dias, parece ter ganho renovada perspectiva: refiro-me, muito em particular, às correlações indivíduo-sociedade e utilidade-prazer.

${ }^{1}$ MUNTEANO, 1967, passim. 
Em tempos oitocentistas, a agudização do antagonismo entre os adeptos kantianos do carácter individual da obra e do seu conteúdo, bem como do princípio do prazer (de inclinação romântica), e os adeptos mais proudhonianos do sentido social da produção artística, aliado à utilidade (de inclinação mais naturalista estes), poderia ser protagonizada por Théophile Gautier e Oscar Wilde, de um lado, e Leo Tolstoi, do outro, o que talvez resulte do contexto sócio-cultural de cada um deles, e com certeza explica alguns dos traços dominantes dos sistemas literários subsequentes dos respectivos países. No célebre ensaio O que é a Arte?, de 1896, Tolstoi contribuiu de forma decisiva para o debate em torno da responsabilidade do artista, ao defender que a arte deveria criar um laço emocional específico entre o criador e o público, de modo a "infectar" o leitor/espectador. Quer dizer que, no entender do escritor russo, a verdadeira arte exigiria a capacidade de unir as pessoas através da comunicação, assente esta em valores como a genuinidade, a sinceridade, a autenticidade e a clareza: "toda a obra de arte", diz Tolstoi, "faz o receptor entrar numa espécie de relação com quem a produziu, ou está a produzila, e também com todos aqueles que, simultânea, prévia ou subsequentemente recebem a mesma impressão artística": a arte seria assim, no seu entender, "um meio de união entre os homens, juntando-nos nos mesmos sentimentos, e indispensável para a vida e o progresso rumo ao bem-estar dos indivíduos e da humanidade" ${ }^{\prime 2}$. Não será preciso muito para avaliarmos a importância destas considerações no entendimento da função social da poesia ${ }^{3}$ que se aprofundará ao longo da primeira metade do século XX.

\footnotetext{
${ }^{2}$ TOLSTOI, 1899, p. 47 ss. Tradução minha, a partir da tradução para inglês de Aylmer Maude.

${ }^{3}$ Faço uso da expressão consagrada por T. S. Eliot no ensaio justamente intitulado "The social function of poetry", proferido pela primeira vez em 1945. Cf. ELIOT, 1956, passim.
} 
Mas sabemos também que a primeira metade do século XX alterou um pouco os dados desta responsabilidade do artista, devido a dois factores histórico-políticos absolutamente decisivos: a propagação da ideologia marxista, por um lado, de fortes consequências partidárias na vida política mas também na literária; e a ascensão do nazismo, resultando na II Guerra Mundial, no respectivo Holocausto e na bomba atómica, que para sempre alterariam os dados estruturantes da consciência infeliz dos autores e o correlativo conceito de expressão artística responsável. Os anos 30 e 40 do século XX assistiram assim a uma eclosão de problemas ético-políticos no seio das questões estéticas, o que explica que, com variações mais ou menos flagrantes, esses decénios tenham assistido ao amadurecimento de obras marcadas por preocupações sócio-políticas: no caso do Brasil, bem expressas no romance regionalista de José Américo de Almeida, Rachel de Queiroz, José Lins do Rêgo ou Graciliano Ramos; em Portugal, no neo-realismo que no final dos anos 30 se instalou no discurso lírico e narrativo; na literatura em língua francesa, num certo Surrealismo empenhado; na literatura em língua inglesa, na determinante Poesia Social de 30, consumada exemplarmente na voz poética de W. H. Auden. Apesar das incontornáveis diferenças entre os diversos sistemas literários nacionais, é iniludível a necessidade que os escritores da época manifestaram de se exprimirem responsavelmente, contrariando aquilo que consideravam ter sido um certo autismo modernista perante o "sentimento do mundo", para usarmos o conhecido título de Drummond que encerra a década, e assumindo assim, agora nas palavras do poeta português Vítor Matos e Sá, a literatura como exibição da "violenta companhia do mundo". É também iniludível o facto de, tanto no caso brasileiro como no português, as obras mais determinantes da época terem obedecido ao princípio sartriano segundo o qual o empenhamento só se poderia consumar integralmente em 
prosa, “império dos signos" verdadeiramente revolucionário e utilitário, incompatível com expressões desadequadas e inúteis como as da poesia, da pintura, da escultura ou da música ${ }^{4}$. Claro que - não será preciso repeti-lo - esta relação entre a expressão estética e a preocupação ético-política configurou-se, em muitos casos, com deformações ao nível das dominantes, prejudicando a dimensão artística das obras devido ao seu servilismo face a factores extra-literários de índole não estética, como a responsabilidade política, a função de revelação e a incitação a agir. Ora, se este conjunto de deformações teve graves consequências na literatura subsequente - e penso já, muito em particular, no caso da literatura portuguesa -, a tal ponto que qualquer compromisso ideológico-partidário detectável no discurso literário passou a ser encarado com desconfiança e até com desprezo nos decénios seguintes, o certo é que o século XXI trouxe consigo uma revitalização flagrante da problemática em torno das correlações indivíduo-sociedade e utilidade-prazer, com uma alteração decisiva: no século XXI, o debate em torno destas correlações trava-se na poesia, não na prosa ${ }^{5}$.

Tendo justamente em conta o reacender desta discussão, em 2011 a rede internacional de pesquisa em poesia LyraCompoetics pediu a vários poetas portugueses, brasileiros e espanhóis que respondessem a um breve inquérito, constituído pelas seguintes questões:

${ }^{4}$ SARTRE, 1993, p. 17 ss. Diz Sartre, numa passagem conhecida: "la prose est utilitaire par essence; je définirais volontiers le prosateur comme un homme qui se sert des mots".

${ }^{5}$ De certa forma, o próprio Sartre chegou a admitir esta possibilidade, ao reconhecer, no seu texto "Orphée noir" - que serve de prefácio a uma colectânea de poesia negra de expressão francesa organizada por Leopold S. Senghor em 1948 -, que a luta de classes se poderia "exprimir poeticamente" (SARTRE, 1948, p. XII). 
A poesia é uma forma de resistência?

Sempre, por definição?

Ou apenas em determinados contextos - sociais, políticos, culturais?

Como pode resistir a poesia e a quê?

Do universo de poetas inquiridos no caso português, vale ressaltar uma evidência: trata-se de um conjunto de mais de duas dezenas de escritores com idades compreendidas entre os 20 e poucos anos (Diogo Vaz Pinto, por exemplo), e os 80 anos (Fernando Guimarães, Herberto Helder), o que permite avaliar as sintonias e variações geracionais nas respostas dadas: como tive já oportunidade de observar num estudo sobre a poesia de Armando Silva Carvalho, é flagrante o gesto unificador de distanciação relativamente a qualquer pendor ideológico do discurso poético que o converta em mera propaganda partidária, naquilo que parece ser ainda uma reacção estética retardada a um certo neo-realismo que pecou por demasiado empenho ou, para utilizarmos uma expressão já consagrada de Todorov, um repúdio daquela "tentação do bem" que, no caso da poesia, pode estar na origem de tantos maus poemas escritos com boa-vontade, como assinalou Fernando Guimarães na sua resposta a este inquérito, na linha de uma questionação que Pablo, personagem de Érico Veríssimo, soube equacionar com toda a pertinência: "Porque há-de o artista ou o escritor estar engajado necessariamente ao Partido Comunista como se este fosse o portador da verdade única, absoluta? Porque não um engajamento total com o homem? Porque não com a vida e todas as suas riquezas e ambiguidades, as suas incontáveis portas,

${ }^{6} \mathrm{O}$ inquérito e as respostas dos poetas encontram-se integralmente disponíveis no endereço http:/ /www.lyracompoetics.org/pt/poesia-eresistencia/. 
caminhos, labirintos e mistérios?"7. Numa análise posterior destas respostas, Ida Ferreira Alves chamou muito agudamente a atenção para o seguinte:

A maior parte dos poetas que responderam ao inquérito amadureceram exatamente nesse período de "engajamento", dos anos trinta a sessenta, e, em decorrência, foram marcados também por uma compreensão da literatura como ação sobre o mundo, como ato de luta ao autoritarismo, vontade de denúncia e inconformismo. Para alguns poetas portugueses, então, que experimentaram as várias décadas de salazarismo, a realidade lhes impunha de forma mais concreta essa necessidade de combate como se formulou num movimento como o Neo-Realismo, o qual ainda mexe com certas sensibilidades críticas e provoca reações acaloradas, pois, de um lado, ficou ligado, nas suas piores realizações, a uma arte sufocada pelas orientações de partido, e, de outro, com seus melhores escritores, problematizou a relação entre escritor, palavra e mundo, gerando atrito, repensando a coisa literária e a função "escritor" em relação às demandas da sociedade, dos seus leitores ${ }^{8}$.

Neste sentido, torna-se especialmente interessante constatar que, concordando todos os autores relativamente àquilo que a resistência poética não é, e que não querem que seja, a unificação se torna mais problemática quando se trata de verbalizar aquilo que a resistência poética é. Aparentemente, portanto, o problema está desde logo nas questões colocadas, se pensarmos que, como alertou Pinson já em 1999, se tornou impossível prosseguir os esforços da Poética no sentido de procurar explicar toda a literatura (toda a poesia) com base

7 VERÍSSIMO, 1965, p. 386.

${ }^{8}$ ALVES, 2013, p. 28. 
num mesmo conceito hegemónico. Na realidade, o problema começa por residir precisamente neste princípio regulador: a hegemonia. Por entre as linhas das respostas dos poetas, há assim um consenso que se vai esboçando: a poesia é, antes de tudo o mais, resistência às múltiplas expressões do poder hegemónico, seja ele o poder da prosa com o seu dizer normativo, o poder dos outros géneros literários, o poder da colectividade e respectiva doxa, o poder dos sistemas económico-políticos neoliberais e de todos os seus "burrocratas indizíveis", na expressiva síntese de Herberto Helder no seu último livro, Servidões ${ }^{9}$, ou o poder do tempo aferido apenas pelos padrões tecnológico-científicos de progresso. Quer dizer, a poesia é resistência na linguagem, é resistência do indivíduo pela preservação do seu direito ao paradoxo, é resistência às leis do mercado e é, naturalmente, resistência essencial às leis da entropia e da morte. O que nos conduz inevitavelmente ao diagnóstico de Antoine Compagnon, de acordo com o qual a literatura seria, em suma, ao mesmo tempo sintoma e solução do mal-estar na civilização ${ }^{10}$.

Façamos então um corte histórico-literário neste conjunto de respostas, procurando isolar as que são da responsabilidade dos poetas cuja obra tem início justamente no início do século XXI, o que os converte numa espécie de vínculo entre as preocupações poéticas do final do século XX e as inovações discursivas e textuais da última década. E comecemos por Manuel de Freitas, lembrando que, em 2002, no conhecido Prefácio à antologia Poetas sem Qualidades, o autor anunciara que "A um tempo sem qualidades, como aquele em que vivemos, seria no mínimo legítimo exigir poetas sem qualidades", sublinhando, em registo

${ }^{9} \mathrm{O}$ expressivo mot-valise é utilizado por Herberto em dois poemas do livro, onde se pode ler também: "sob a força devastadora da poesia / os burrocratas os burrocratas" (HELDER, 2013, p. 85-6).

${ }^{10}$ Cf. COMPAGNON, 2010, p. 33. 
benjaminiano, que "a qualidade passou a ser, nas sociedades industrializadas, sinónimo de quantidade", e propondo uma "ética da contemporaneidade" assente na perda da auréola, para concluir: "Podemos [...] encontrar em todos eles [os poetas antologiados] um sentido agónico (discretíssimo, por vezes) e sinais evidentes de perplexidade, inquietação ou escárnio perante o tempo e o mundo em que escrevem. [...] Comunicam, em suma"11. Um ano depois, numa colaboração para a revista Relâmpago, Manuel de Freitas proporia uma releitura do célebre epigrama de Novalis, a poesia é "o autêntico real absoluto", confessando: "a poesia não é, para mim, o autêntico real absoluto. Será, quando muito, o ameaçado real possível. Quanto mais doloroso, mais verdadeiro"12. Na resposta ao inquérito da LyraCompoetics, o poeta acrescenta:

Num mundo como aquele em que vivemos, a poesia é, quase fatalmente, uma forma de resistência. Resistência à hegemonia de outros géneros literários ou (sub)produtos culturais, que a remete para uma quase invisibilidade, mas também resistência à massificação, ao espectáculo pseudocultural e à degradação quotidiana do verbo.

A poesia, como toda a arte, é ainda uma forma de resistência à morte, à monotonia, à insipidez dos dias e das palavras. No actual contexto português, a poesia pode (e deve) ser também uma forma de resistência ao infame acordo ortográfico, cuja prática virá trazer à língua as mais indesejáveis e apoéticas ambiguidades, entre outras consequências nefastas e dificilmente justificáveis.

A poesia resiste por ser essa a sua condição, porque toda a grande poesia provém de uma urgência de dizer, mais do que de uma escolha ou de um projecto.

${ }^{11}$ FREITAS, 2002, p. 9 e 14.

${ }^{12}$ FREITAS, 2003, p. 145. 


\section{$[\ldots]$}

A poesia resiste porque não pode ser adiada - para outro tempo, lugar ou voz. Nesse exacto sentido, e como já Goethe afirmou, a poesia é circunstancial. E resiste/responde, muitas vezes, a circunstâncias tão exactas quanto reconhecíveis: um luto, um encontro, um concerto de música, uma viagem.

Se há uma preocupação por parte de Freitas em destacar a importância da resistência em poesia face aos hipermercados artísticos e literários que dominam o panorama actual da cultura portuguesa, o certo é que o autor não deixa de colocar a tónica naqueles que são os dois factores constituintes mais elementares do texto poético: a sua específica dimensão verbal, e o modo de instituição de uma relação singular com o mundo, onde o culto da referencialidade não significa necessariamente a perda da dimensão estética da obra. De facto, quando Freitas defende que a poesia resiste "à degradação quotidiana do verbo", associando esta degradação aos problemas da massificação e do espectáculo pseudo-cultural, está justamente a chamar a atenção para a função social da palavra poética, num sentido muito semelhante àquele que Rosa Maria Martelo viria a aprofundar num texto recente, iluminado pela leitura crítica dos versos de Manuel Gusmão "Não consentir na humilhação da linguagem: ela / não faz tão pouco ruído quanto o silêncio imposto / impõe; o poema é o que estende ao máximo de comum"13. Mas antes façamos um breve parêntesis para lembrar que, se reconstituirmos uma genealogia muito cara aos poetas desta geração, nunca será demais convocar o tratamento que, em tempos mais remotos, Jorge de Sena deu precisamente a esta questão da "humilhação da linguagem", mediante o seu conceito de "fidelidade", magnificamente exposto num poema de Conheço o Sal...:

${ }^{13}$ GUSMÃO, 2008, p. 75. Cf. MARTELO, 2013, p. 5-13. 


\begin{abstract}
Estão podres as palavras - de passarem por sórdidas mentiras de canalhas que as usam ao revés como o carácter deles.

E podres de sonâmbulos os povos ante a maldade à solta de que vivem a paz quotidiana da injustiça.

Usá-las puras - como serão puras, se caem no silêncio em que os mais puros não sabem já onde a limpeza acaba e a corrupção começa? Como serão puras se logo a infâmia as cobre de seu cuspo? Estão podres: e com elas apodrece o mundo e se dissolve em lama a criação do homem que só persiste em todos livremente onde as palavras fiquem como torres erguidas sexo de homens entre o céu e a terra. ${ }^{14}$
\end{abstract}

No ensaio mencionado, Rosa Maria Martelo revisita o motivo da novilíngua inventada por George Orwell na conhecida distopia 1984 à luz do neo-liberalismo imperante na sociedade ocidental contemporânea, chamando a atenção para o processo que consiste em "destruir palavras para o que elas significavam nunca mais possa sequer voltar a ser pensado", e assim criar, com o empobrecimento do léxico, um "pobre mundo novo" ao serviço da ideologia feita senso comum. Diagnóstico que, no caso específico português, seria ainda mais grave tendo em conta aquele traço do carácter colectivo nacional que, na crua análise de Eduardo Lourenço no estudo Psicanálise mítica do destino português (1977-78), consistiria em sermos "um povo naturalmente destinado à subalternidade"15. Contudo, sublinha Rosa Martelo numa constatação muito afim das respostas de Manuel de Freitas (onde não deixam também de ressoar as reflexões de

\footnotetext{
${ }^{14}$ SENA, 1989, p. 223.

${ }^{15}$ LOURENÇO, 1988, p. 21.
} 
Barthes sobre a escrita como processo de resistência ao fascismo da língua), "sintomaticamente, esta novilíngua não entra bem nas artes nem na literatura", pois existe "uma incompatibilidade fundamental entre poesia e senso comum" graças à "experimentação discursiva, [à] convergência idiomática entre som e sentido, ou entre som e imagem verbal"16. Não por acaso, este estudo de Rosa Martelo tem como epígrafe a resposta que um outro poeta da mesma geração de Manuel de Freitas, José Miguel Silva, deu ao inquérito mencionado. Nela, Silva sustenta que a intenção de resistência poética incide sobre a "fealdade", a "mentira" e a "estupidificação promovidas pelos oligopólios de comunicação social", para concluir:

Nesse desiderato, um poeta não pode deixar de declarar guerra a todo o género de clichés: verbais, desde logo, mas também políticos, filosóficos, psicológicos, etc. Mas sem nunca perder de vista que, numa era de comunicação de massas, essa sua guerra é tão desigual, e portanto tão caricata, como a guerra que uma sardinha (zangada) decidisse mover a um petroleiro (de aço).

José Miguel Silva, cuja obra se iniciou em 1999 com o livro O Sino de Areia, retoma um motivo muito caro a um poeta como o russo Joseph Brodsky, que no ensaio "How to read a book" declarou, sem meios-termos: "a resistência ao cliché é o que distingue a arte da vida"17. Mas, de certa forma, José Miguel Silva também parece reescrever o dictum de Sartre segundo o qual nunca nenhum poema terá impedido uma criança de morrer, como de resto o dirá exemplarmente no poema "Exame de estética", do livro Vista para um Pátio seguido de Desordem:

${ }^{16}$ MARTELO, 2013, p. 12.

${ }^{17}$ BRODSKY, 1995, p. 86. 
EXAME DE ESTÉTICA

My rock E roll friend.

The Go-Betweens

Eu estava na Lavandeira à espera do César que me prometera 10 gramas para as 6,30 quando um desgraçado me trouxe a notícia de que o Artur fora encontrado em casa com a morte a correr-lhe nas veias.

Oh terríveis 6 horas da tarde, eu tinha na manhã seguinte um exame de Estética e a questão era responder para que serve a arte, se não impede a mudança, se não faz que estejas aqui ao pé de nós a ouvir o último dos Go-Betweens.

Não serve para muito, serve apenas para escudar uma sombra, para escorar as lágrimas, para que a morte não seja a penúltima a rir. ${ }^{18}$

Recentemente, Silva repetiu a mesma constatação em Erros Individuais, de 2010: "Voltemos a isto, à contagem dos erros / na soma do mundo, à impotência do riso / contra tudo o que não sabemos mudar: / a morte, o egoísmo, o levadiço coração / humano"19. O facto de habitarmos um tempo pós-Auschwitz parece poder perturbar ainda mais esta reflexão, sobretudo se tivermos em mente a filosofia moral de Adorno e a sua célebre fórmula, segundo o qual escrever poesia depois de Auschwitz seria "bárbaro". A invalidade — ou invalidez — da literatura depois de Auschwitz tem na sua raiz um pressuposto moral iniludível, que interfere directamente na escrita, porquanto o bárbaro, num sentido que aqui importa resgatar, é justamente

${ }^{18}$ SILVA, 2003, p. 42.

${ }^{19}$ SILVA, 2010, p. 11. 
o que não escreve. Depois de Adorno, por conseguinte, depois de Auschwitz, depois da banalidade do mal denunciada por Hannah Arendt, a escrita só pode ser uma não-escrita, a ética aprisiona a estética, não a deixa articular-se em linguagem. Ainda assim, este é o lugar da mais pura aporia, já que, desde Auschwitz, tal aprisionamento tem levado a Arte, e a Literatura em particular, a construir um percurso pautado por uma procura que as palavras de Beckett magnificamente exprimem: "No matter. Try again. Fail again. Fail better". Assim, depois de Auschwitz, os livros bem escritos são os que falham de novo para falhar melhor. E também aqui não há livros morais ou imorais, como quis Oscar Wilde. Imoral é não tentar de novo. Imoral é não falhar de novo para falhar melhor. Imoral é não escrever. Imoral é não escrever bem. Talvez o Gilbert de Wilde agora já pudesse dizer que toda a arte é, em última instância, profundamente moral.

Por outras palavras e num outro registo discursivo, é exactamente a isto que José Miguel Silva, um dos mais importantes e singulares poetas da sua geração, procurará dar resposta ao longo de toda a sua obra, mediante o culto continuado de uma muito especial ironia cínica que repudia todos os tabus em nome da verdade poética, entendida como a única forma possível de dizer o mundo, ou de usar as palavras como "figuras do imundo", na feliz expressão de MiguelManso $^{20}$. Por isso podemos ler, ao longo dos seus versos, declarações tão escandalosas como a que dá título a estas considerações - "Às vezes o amor / degenera em violência. Ao terror do outro / respondemos com pedradas cegas. / Aflitos por não compreender", ou "Um ser humano é um combinado de egoísmo, / sofrimento e necedade. Não comove ninguém", ou "Só o mal pode vencer o mal, pois o bem não tem / poder; tem

${ }^{20}$ Em "Antimundo", poema que integra o livro Ensinar o Caminho ao Diabo, de 2012. 
apenas compaixão, fadiga e compaixão", ou poemas inteiros, como este, de Movimentos no Escuro:

FOGO-FÁTUO - LOUIS MALLE (1963)

Se cada um fizesse a sua parte, o mundo seria um lugar perfeito: a despovoada alegria dos montes, as ruas esmaltadas de verdura, os séculos sem rumo nem História.

Utopia menos dúbia não conheço do que esta. E era tão simples: bastava que cada um abdicasse um pouco do nó cego a que chamamos eu, dessa falsa confiança,

uma vida a conta-gotas. Bastava um tiro certeiro, um nó corredio, um saco de plástico a fechar no pescoço. Mas não, deixemo-nos de sonhos revolucionários:

a paz na Terra só virá por acidente (vascular-cerebral, ao volante, o que for). Somos todos egoístas, frívolos, vivos, incapazes de um gesto despoluidor.

Eu próprio, que devia dar o exemplo, estou sentado na cozinha a tentar decidir-me entre pão com manteiga e bolachas de centeio, enquanto a chaleira, no fogão, assobia para o $a^{2} .^{21}$

Não é difícil perceber de onde resulta o desconforto que estes versos de imediato provocam no leitor, numa imposição clara do princípio da jouissance em detrimento do do prazer $^{22}$ : por

${ }^{21}$ SILVA, 2005, p. 34.

${ }^{22}$ Lanço mão, naturalmente, da dualidade consagrada por Roland Barthes, segundo a qual o "texto de prazer" seria o texto que contenta, 
um lado, o cinismo que rege a enunciação vem contrariar toda uma tradição poética essencialmente elíptica e metafórica, assente no tabu, mediante a adopção de uma atitude deliberadamente imoral que consiste em defender um ponto de vista escandaloso pois, ao contrário do tabu, onde se proíbe porque se arde de vontade de profanar, no cinismo profana-se para aprofundar o respeito e não deixar nada implícito ou latente ${ }^{23}$; por outro lado, o desconforto deriva directamente do modo como, através desta estratégia cínica fundada num princípio de autenticidade, o poeta consegue "infectar" o leitor, como queria Tolstoi, e com isso gerar empatia e torná-lo também uma consciência responsável. Quer dizer: lá onde o leitor sempre manteve, apesar de tudo, uma distância bastante confortável perante a enunciação poética, criase agora um vínculo ético - de base interlocutiva -, que implica a partilha da consciência infeliz perante o mal-estar da civilização, e é justamente aqui que reside o grande poder de comunicabilidade desta poesia, e o modo evidente como nela se manifesta o agapè, essa forma de amor humanista que Luc Ferry considera ser o grande amor do século XXI, substituindo-se a eros (o amor que se alimenta da falta do outro) e a philia (o amor que se compraz apenas com a sua presença $)^{24}$. Manuel de Freitas mencionará, a propósito desta atitude, um misto de "responsabilidade e insubmissão" enquanto expressão de fidelidade ao "indivíduo e [à] condição humana" de que faz parte ${ }^{25}$.

que preenche, que provoca euforia, que não rompe com a cultura e que por isso se encontra ligado a uma "prática confortável da leitura", ao passo que o "texto de gozo" seria aquele que coloca o leitor em estado de perda, que faz vacilar as suas certezas, que põe em crise a sua relação com a linguagem, isto é, que desencadeia uma prática desconfortável da leitura (BARTHES, 1973, p. 25-6).

${ }^{23}$ De acordo com a síntese de Jankélévitch (1964, p.118.).

${ }^{24}$ FERRY, 2011, passim; FERRY, 2012, passim.

${ }^{25}$ FREITAS, 2006. Apud MARTELO, 2010, p. 316. 
Eis a chave: a condição humana, isto é, nos termos de Ortega y Gasset, a (re) humanização da arte. Agora, ao contrário do que aconteceu nos anos 30 e 40 do século passado, não se trata de usar a literatura para manifestar preferências ideológicopartidárias ou idiossincrasias políticas. Como não se trata de escrever movido por princípios apriorísticos ou extra-literários. Agora, ao contrário de então, há preocupações históricas e sócio-políticas muito sérias que transpiram de muitos versos, mas elas dizem respeito, antes de tudo mais e para usarmos um conhecido título de Pico della Mirandola que José Miguel Silva convocou para epígrafe de um dos seus últimos livros ${ }^{26}$, à dignidade do homem fundada em valores tão elementares como a liberdade e a justiça: "E o pior é que chamamos liberdade / a um tapete rolante que, rolante, já não ouve / a opinião dos nossos pés; que nos leva / para onde e anuímos, alheados, / aos mecânicos desígnios do terror. / / Respiramos cadeados, consumimos injustiça / damos duas várias voltas ao risonho torniquete / que nos serve de chapéu"27.

É nesta exacta medida que a poesia portuguesa contemporânea é agónica: ela constrói-se como dicção crítica, ela interroga e questiona as representações do senso comum, ela faz-se pela mão de autores implicados que convocam leitores implicados, ela é transgenérica porque rejeita as diferenciações impostas e prefere associar a intensidade lírica à extensão narrativa, ela propõe mundos e formas de vida alternativos face à hegemonia económico-financeira, ela adopta uma atitude de representação funcional naturalista e de fantasia concretizante. O que explica também que esta geração de poetas tenha aliado o seu talento individual a uma tradição bastante distinta da que imperara nas últimas décadas do século XX, convocando para si autores como Jorge de Sena e Cesariny, Alexandre O’Neill e

${ }^{26}$ SILVA, 2010, p. 15 ss.

${ }^{27}$ SILVA, 2002, p. 19. 
Fernando Assis Pacheco, a par de um significativo grupo de poetas literalmente resistentes, como os polacos Czesław Miłosz, Zbigniew Herbert ou Wisława Szymborska. Em suma, a melhor poesia portuguesa contemporânea é de facto, como deseja JeanClaude Pinson, uma po-ética ${ }^{28}$, na justa medida em que, graças ao seu pendor hiper-denotativo, ela é profundamente humanista, ao cultivar uma aguda consciência cívica da novidade do horror ou do seu retorno, e assim assegurando o sentido de escândalo que, como sugeriu George Steiner, nos deve levar a ter sempre em mente as palavras de Emily Dickinson: é preciso "preservar uma alma terrivelmente espantada"29.

28 PINSON, 2008; PINSON, 2013.

${ }^{29}$ Cf. STEINER, 1992, p. 57. 


\section{Referências bibliográficas}

ALVES, Ida Ferreira. "Sobre respostas de poetas resistentes". eLyra, 2, 2013. http:/ / www.elyra.org/index.php/elyra/article/view/24

BARTHES, Roland. “La Bruyère» (1963). In: Essais critiques. Paris: Seuil, 1991.

BARTHES, Roland. Le plaisir du texte. Paris: Seuil, 1973.

BRODSKY, Joseph. "How to read a book". In: On grief and reason : essays. Londres : Penguin, 1995.

COMPAGNON, Antoine. Para que serve a literatura? Trad. José Domingues de Almeida. Porto: Deriva, 2010.

ELIOT, T. S. "The social function of poetry". In: On poetry and poets. Londres: Faber \& Faber, 1956.

FERRY, Luc. A revolução do amor: para uma espiritualidade laica. Lisboa: Temas e Debates / Círculo de Leitores, 2011.

FERRY, Luc. De l'amour: une philosophie pour le XXIe siècle. Entretien avec Claude Capelier. Paris: Odile Jacob, 2012.

FREITAS, Manuel de. "O tempo dos puetas". Pref. a Poetas sem qualidades. Lisboa: Averno, 2002.

FREITAS, Manuel de. "Glass enclosure". Relâmpago, 12. Lisboa: Fundação Luís Miguel Nava, Abril de 2003.

FREITAS, Manuel de. "Sem complacências". Expresso / Actual. Lisboa, 11 de Fevereiro de 2006.

GUSMÃO, Manuel. A terceira mão. Lisboa: Caminho, 2008.

JANKÉLÉVITCH, Vladimir. L'Ironie. Paris: Flammarion, 1964.

LOURENÇO, Eduardo. "Psicanálise mítica do destino português" (1977-78). In: O labirinto da saudade. Lisboa: Dom Quixote, 1988.

LYRACOMPOETICS. “Inquérito sobre Poesia e Resistência”. http:/ / www.lyracompoetics.org/pt/poesia-e-resistencia/

MARTELO, Rosa Maria. "Alegoria e autenticidade". In: A forma informe: leituras de poesia. Lisboa: Assírio \& Alvim, 2010. 
MARTELO, Rosa Maria. "Questões de vocabulário". Cão celeste, 4. Lisboa: Averno, Novembro de 2013.

MIGUEL-MANSO. Ensinar o caminho ao diabo. Edição de autor, 2012. MUNTEANO, B. Constantes dialectiques en littérature et en histoire. Paris: Marcel Didier, 1967.

PINSON, Jean-Claude. A Piatigorsk: sur la poésie. Nantes: Editions Cécile Defaut, 2008.

PINSON, Jean-Claude. Poéthique: une autothéorie. Seyssell: Champ Vallon, 2013.

SARTRE, Jean-Paul. “Orphée noir”. In: SENGHOR, Leopold Sédar (org.). Anthologie de la nouvelle poésie nègre et malgache de langue française. Paris: PUF, 1948.

SARTRE, Jean-Paul. Qu'est-ce que la littérature? Paris: Seuil, 1993.

SENA, Jorge. "Conheço o sal... e outros poemas". In: Poesia-III. Lisboa: Edições 70, 1989.

SILVA, José Miguel. Ulisses já não mora aqui. Lisboa: \& etc., 2002.

SILVA, José Miguel. Vista para um pátio seguido de Desordem. Lisboa: Relógio d'Água, 2003.

SILVA, José Miguel. Movimentos no escuro. Lisboa: Relógio d'Água, 2005.

SILVA, José Miguel. Erros individuais. Lisboa: Relógio d'Água, 2010.

STEINER, George. No castelo do Barba Azul: algumas notas para a redefinição da cultura. Lisboa: Relógio d'Água, 1992.

TOLSTOI, Leo. What is art?. Trad. e introd. Aylmer Maude. Nova Iorque: Funk \& Wagnalls Company, 1899.

VERÍSSIMO, Érico. O senhor embaixador. Porto Alegre: Editora Globo, 1965. 


\section{Resumo}

Com base numa perspectivação histórico-literária de alguns dos problemas mais prementes da criação poética, em particular os mais directamente relacionados com a responsabilidade ético-cívica do artista, este estudo leva a cabo uma reflexão crítica sobre o discurso poético português contemporâneo. Equacionam-se algumas questões específicas desse discurso, a partir da obra poética de autores como Manuel de Freitas e José Miguel Silva, sobrelevando os dispositivos enunciativos e textuais que marcadamente caracterizam a expressão da poesia portuguesa actual.

\section{Abstract}

Based on a historical-literary perspective of some of the most pressing problems of poetic creation, in particular those most directly related to the ethical and civic responsibility of the artist, this study carries out a critical reflection on the contemporary Portuguese poetic discourse. We discuss some specific issues of this speech, analysing the poetic works of authors such as Manuel de Freitas and Jose Miguel Silva, through the emphasis on the enunciative and textual devices that markedly characterize the expression of the current Portuguese poetry. 
